\title{
Spinal Cord Editor's Page May 2007
}

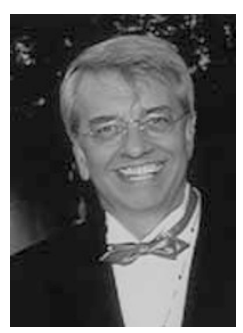

\section{Dear Spinal Cord reader,}

It is not so long ago that sexuality in people with spinal cord injury was something of a taboo subject. The denial of its existence and belief that it was inappropriate to discuss the issue with patients was commonplace. Such opinions have now become rare because of our increasing knowledge about all aspects of sexual function, including developments in philosophy and ethics, and changing views about sexuality in the general population. The topic has become open for discussion, research and specialized treatment.

At the same time, great improvements in the management of patients with spinal cord injury, the increased prognosis for survival and the importance given to quality-of-life issues by society, have led both patients and carers to emphasize the importance of addressing sexuality as an integral component of the comprehensive management of spinal cord injury.

One should not forget that a significant proportion of patients with spinal cord lesions are young. As a practicing clinician, my contact with patients within days after acute admission has taught me that questions about sexual function are among the most urgent ones they wish to ask. Partners and families also need to remain informed. The discussion is generally brief at this stage, but should be taken up again during rehabilitation.

The May issue of Spinal Cord includes three manuscripts on sexuality by Anderson and colleagues that contain important data in relation to several aspects of sexual function and spinal injury:

- The impact of spinal cord injury on sexual function: concerns of the general population

- Long-term effects of spinal cord injury on sexual function in men: implications for neuroplasticity

- Spinal cord injury influences psychogenic as well as physical components of female sexual ability.

Three animal experiments follow the studies by Anderson and co-workers: the first examines sleep patterns over a 15-day period in rats with spinal cord injury; the second investigates the spontaneous recovery of hindlimb movement in spinal cord transected mice; and the third looks at the influence of the intensity, level and phase of spinal cord injury on the proliferation of $\mathrm{T}$-cells and T-cell-dependent antibody reactions in the rat.

Finally, a case report on complete medulla/cervical spine transection after atlanto-occipital dislocation is followed by two Letters to the Editor that bring this issue to a close. We are keen to encourage debate and discussion among Spinal Cord's readership, and hope that more letters to the editor shall follow in future issues of the journal.

Many of our readers will know that stricter word limits were introduced for Spinal Cord articles in 2006. Experience tells us that concise reports are generally more effective at communicating their message. For extensive studies, we recommend these be submitted to the journal in parts, so that each component of the study receives the attention it deserves - please contact the Spinal Cord Editorial Office if you have any questions about this before submission.

Spinal Cord (2007) 45, 327. doi:10.1038/sj.sc.3102068

J-J Wyndaele

Editor-in-Chief

E-mail: spinalcord@uza.be 